\title{
Chronic uterine inversion associated with uterine leiomyoma misdiagnosed as cervical fibroid: a case report
}

\author{
Swati Kochar, Ankur Nama*, Santosh Khajotia, Neha Suthar
}

Department of Obstetrics and Gynaecology, S.P.M.C. and A.G.H. Bikaner, Rajasthan, India

Received: 27 August 2019

Accepted: 30 September 2019

\section{*Correspondence:}

Dr. Ankur Nama,

E-mail: ankurnama.spmc@gmail.com

Copyright: (C) the author(s), publisher and licensee Medip Academy. This is an open-access article distributed under the terms of the Creative Commons Attribution Non-Commercial License, which permits unrestricted non-commercial use, distribution, and reproduction in any medium, provided the original work is properly cited.

\begin{abstract}
Chronic inversion of uterus is a rare clinical entity which is usually associated with obstetrics complication and rarely with gynaecological disorder like fibroid present at fundus of uterus. We here present a case of 40-year-old female P3L3 with chronic inversion of uterus with fundal fibroid which present with 3year history of abnormal vaginal bleeding. Ultrasonography and MRI revealed cervical fibroid. Due to AUB secondary to cervical fibroid decision of hysterectomy was taken. On laparotomy chronic uterine inversion was present which was corrected by haultain's procedure. Then hysterectomy was done. Histopathology report suggestive of uterine leiomyoma at fundus of uterus. Chronic uterine inversion associated most commonly with fundal submucous leiomyoma. Other causes are leiomyosarcoma, endometrial carcinoma, cervical carcinoma, rhabdomyosarcoma, mixed mullerian sarcoma. It is an extremely rare gynaecological condition and can be misdiagnosed as cervical fibroid, advanced cervical malignancy or other causes of AUB in females. It could be labelled as gynaecological near miss so a high index of suspicion is necessary for it's diagnosis.
\end{abstract}

Keywords: Cervical fibroid, Chronic uterine inversion, Fundal fibroid, Gynaecological near miss, Haultain's procedure, Hysterectomy

\section{INTRODUCTION}

Uterine inversion is descent of fundus of uterus to or through cervix, so uterus is turned inside out. ${ }^{1}$ It is a rare life-threatening complication of parturition, which usually occur immediately after delivery. ${ }^{2}$ Chronic inversion is rarer and most of the times associated with uterine pathology like uterine fibroid, uterine neoplasm, endometrial polyp. ${ }^{3}$ Authors present a case of chronic uterine inversion which was diagnosed during laparotomy done for hysterectomy due to AUB secondary to cervical fibroid.

\section{CASE REPORT}

A 40-year-old P3L3 premenopausal woman came to our OPD with a 3year history of excessive menstrual flow, severe dysmenorrhea and inter-menstrual bleeding with PBAC score 350 associated with lower abdominal pain and dizziness. Her past medical and surgical history were normal. She had normal bowel habit but had sometimes retention of urine.

General physical examination revealed pale woman with no icterus and edema. Her BP was 110/70 mmHg. Pulse rate was 110 beats per minute. Her cardiorespiratory system was normal.

Per abdominal examination revealed nothing remarkable and no palpable pathology. On local examination no mass present outside vagina. On per speculum examination a mass of $6 \times 5 \mathrm{~cm}$ present in vagina which was congested, edematous and red in appearance. On per vaginal examination a mass of $6 \times 5 \times 5 \mathrm{~cm}$ was felt in vagina 
which was firm in consistency, bleeds on touch with smooth outline. The mass was occupying whole of the vagina so it was not possible to do examination above the mass. Also, there was excessive bleeding hindering further examination. Cervical malignancy was ruled out by histopathology of tissue obtained during per vaginal examination.

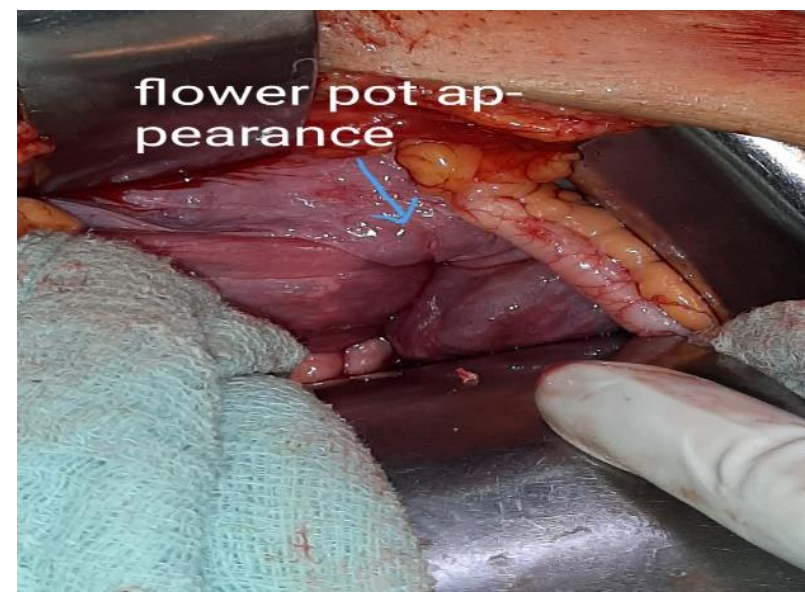

Figure 1: Illustrating flower pot appearance which shows a constriction ring through which Cornu fundal structures are dipping into it.

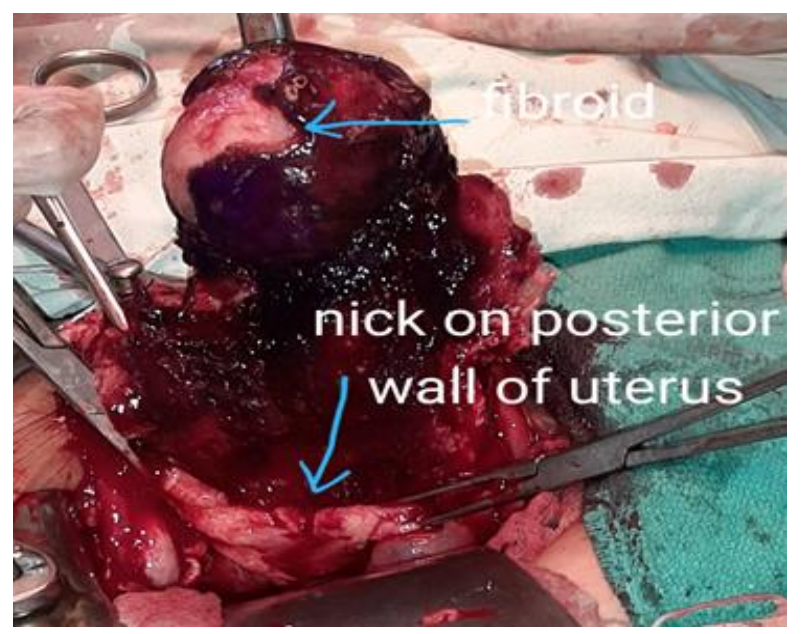

Figure 2: A fundal submucosal fibroid with incision on posterior wall of uterus for Haultain's procedure.

Her investigations were; $\mathrm{Hb} 7 \mathrm{gm} / \mathrm{dl}$, after that 3 unit of blood transfusion was done. Her ultrasonography revealed bulky uterus with cervical fibroid and her MRI was suggestive of cervical fibroid. ECG, chest X-ray, renal and liver function test were normal. So provisional diagnosis of cervical fibroid was made. She was given broad spectrum antibiotics and planned for hysterectomy as her bleeding did not resolve on medical management.

Under epidural anaesthesia patient's abdomen opened and after opening the abdomen findings were - there was absent uterine fundus, a cervical constriction ring and a classical mouth of flower pot appearance (Figure 1).
Incision was given on posterior surface of the constriction ring and then inverted fundus was pushed up from below with an assistant passing a finger through the vagina. Thus, inversion was reduced (Figure 2). Then pulled-up inverted uterus with fundal fibroid was removed by total abdominal hysterectomy.

Specimen was taken out and sent for histopathology. On cut section there was a fibroid of $6 \times 5 \mathrm{~cm}$ present at fundus of uterus. Abdomen closed back in layers after hemostasis and after checking counts. Post-operative period uneventful. Patient was healthy at time of discharge. Her histopathology revealed uterine leiomyoma.

\section{DISCUSSION}

Uterine inversion defined as descent of fundus of uterus to or through the cervix, so uterus is turned inside out. ${ }^{1}$ It may be puerperal and non-puerperal.

Chronic non-puerperal uterine inversion is an extremely rare condition accounting for approximately $1 / 6^{\text {th }}$ cases of all uterine inversion. Benign uterine tumors (leiomyoma, endometrial polyps) was the most common cause and associated $70-80 \%$ cases of uterine inversion. ${ }^{2}$

Exact mechanism causing uterine inversion are not clearly identified. Possible mechanisms are - sudden emptying of uterus which was distended by tumor, thinning of the uterine walls due to an intrauterine tumor, dilatation of cervix. ${ }^{4}$

High index of suspicion is necessary for the diagnosis. Diagnosis depends on clinical feature, pelvic examination and imaging techniques. Chronic inversion presents with irregular vaginal bleeding, severe dysmenorrhea, chronic vaginal discharge, weakness, backache and anaemia. ${ }^{5}$ On pelvic examination a mass coming through the cervix, absence of the uterine fundus during bimanual or rectal examination fully indicative of the chronic uterine inversion. 5

First line investigation includes ultrasonography. ${ }^{6}$ Best imaging modality if available is the MRI. ${ }^{5}$ Although, it will only assist the diagnosis. Due to rare type of disorder sometimes diagnosis will be made during surgery. ${ }^{7}$

It's diagnosis and management could be challenging because it is rarely encountered by the gynaecologist. ${ }^{3}$

Surgery is essential in chronic non-puerperal uterine inversion. Surgical repositioning or hysterectomy can be done considering patient's age, procreative desire and associated condition.

Surgical repositioning can be done through vaginal or abdominal approaches. In vaginal route approach Spinelli's method requires dissection of bladder with 
anterior uterine wall incision whereas in Kustner's method posterior uterine wall incision is given. ${ }^{8}$

In abdominal approach a) Huntington's procedure consist of locating the cup of uterus formed by inversion, digitally dilatation of the cervical ring and gentle upward traction of round ligament of the uterus. ${ }^{9}$ b) Haultain's method- Vertical incision is given on posterior parts of the constriction ring, each round ligament from slit is pulled upwards while an assistant pushes the fundus upwards through vagina. ${ }^{10}$

Other methods include laparoscopic reduction, use of obstetric ventouse at laparotomy and robotically assisted laparoscopic reduction. We used the Haultain's method to reposit the uterus.

\section{CONCLUSION}

It is an extremely rare gynaecological condition that is difficult to diagnose for even experienced gynaecologist and radiologist. It can be misdiagnosed as cervical fibroid, advanced cervical malignancy or other causes of AUB in females. It could be labelled as "gynaecological near miss" so a high index of suspicion is necessary for its diagnosis.

Funding: No funding sources

Conflict of interest: None declared

Ethical approval: Not required

\section{REFERENCES}

1. Lai FM, Tseng P, Yeo SH, Tsakok FHM. Non puerperal uterine inversion: a case report. Singapore Med J. 1993;34:466-8.

2. Gomez-Lobo, V, Burch, W. Nonpuerperal uterine inversion associated with an immature teratoma of the uterus in an adolescent. Obstet Gynecol. 2008;112:708-9.
3. Omololu OM, Rabiu KA, Quadri MA, Oyedeko MO, Fatogun YM. Non puerperal uterine inversion due to Submucous fibroid: a case report. Niger Postgrad Med J. 2011;18:158-60.

4. Lupovitch A, England ER, Chen R. Nonpuerperal uterine inversion in association with uterine sarcoma: case report in a 26-year-old and review of the literature. Gynecol Oncol. 2005;97(3):938-41.

5. Occhionero M, Restaino G, Ciuffreda M, Carbone A, Sallustio G, Ferrandina G. Uterine inversion in association with uterine sarcoma: a case report with MRI findings and review of the literature. Gynecol Obstet Invest. 2012;73(3):260-4.

6. $\mathrm{Hu} \mathrm{CF}$, Lin $\mathrm{H}$. Ultrasound diagnosis of complete uterine inversion in a nulliparous woman. Acta Obstetricia et Gynecologica Scandinavica. 2012;91(3):379-81.

7. Umeononihu OS, Adinma JI, Obiechina NJ, Eleje GU, Udegbunam OI, Mbachu II. Uterine leiomyoma associated non-puerperal uterine inversion misdiagnosed as advanced cervical cancer: a case report. Int J Surg Case Rep. 2013;4(11):1000-3.

8. Fofie CO, Baffoe P. Non puerperal uterine inversion: a case report. Ghana Med J. 2010;44:79-81.

9. Huntington JL. Abdominal reposition in acute inversion of the puerperal uterus. AM J Obstet Gynaecol. 1928;15:34-40.

10. Haultain F. The treatment of chronic uterine inversion by uterine hysterectomy. BMJ. 1901;2:974-80.

Cite this article as: Kochar S, Nama A, Khajotia S, Suthar N. Chronic uterine inversion associated with uterine leiomyoma misdiagnosed as cervical fibroid: a case report. Int J Reprod Contracept Obstet Gynecol 2019;8:4593-5. 